\title{
Beneficial Effect of Calcium Supplementation on Bone Mineral Density of Calcium Deficient Adolescents
}

\author{
Gunjan Soni, Gursharan Kaur Kochar, Gurpreet Kaur
}

Department of Home Science, Kurukshetra University, Kurukshetra, India

Email address:

vermgunjan@gmail.com (G. Soni), kocharcup@gmail.com(G. K. Kochar), Mail2gurpreetarora@gmail.com(G. Kaur)

\section{To cite this article:}

Gunjan Soni, Gursharan Kaur Kochar, Gurpreet Kaur. Beneficial Effect of Calcium Supplementation on Bone Mineral Density of Calcium Deficient Adolescents. International Journal of Food Science and Biotechnology. Vol. 3, No. 3, 2018, pp. 83-88.

doi: $10.11648 / j . i j f s b .20180303 .12$

Received: June 27, 2018; Accepted: August 23, 2018; Published: October 10, 2018

\begin{abstract}
The supplementation of calcium during growth years may help in bone formation. Insufficient intake of calcium does not produce obvious symptoms since the body maintains calcium levels in the blood by taking it from bones. Therefore, the present study was undertaken with an objective to assess the beneficial effect of calcium supplementation on the bone mineral density of calcium deficient adolescents. The feeding trial was performed on select set of adolescent students - 48 female and 65 male subjects. These selected subjects for experimental feeding trial were sub-divided into three groups, comprising one control and two supplemental fed groups COS (Calcium organic supplement), CIS (Calcium inorganic supplement). Statistical analysis of T-Score before and after feeding trial indicated, that for males, a significant difference was observed in calcium organic supplement $(\mathrm{p}=0.0006)$, while, no significant difference was observed for male's control and inorganic calcium supplement. Female groups indicated significant difference for OCS $(\mathrm{p}=0.0137)$ and ICS $(\mathrm{p}=0.0084)$ while no significant difference was observed for control. In conclusion, significant increase in Bone mineral density were observed among male and female subgroups after intervention. Also, Organic supplements had a greater effect on BMD.
\end{abstract}

Keywords: Adolescence, Bone Mineral Density, Calcium Deficiency, p-DEXA, Osteopenia

\section{Introduction}

Calcium is a major element in bones. The bones need plenty of calcium throughout childhood and adolescence to reach their peak strength and calcium contents by about age of 30 year. After that, bones slowly lose calcium. Less intake of calcium severely affects the bones and results in poor bone density. This can be quite a serious condition for children and adolescents as it may lead to easy fractures, muscular aches, and spasms, and in extreme cases rickets. Hence, adequate dietary calcium intake is necessary for infants, children and adolescents in order to is necessary for the attainment of peak bone mass to reduce risk of fractures and osteoporosis in the later life. The supplementation of calcium at this stage may help in bone formation. Insufficient intake of calcium does not produce obvious symptoms since the body maintains calcium levels in the blood by taking it from bones. However, over the long term, inadequate intake of calcium (below recommended levels) produces serious health consequences, such as causing low bone mass (osteopenia) and increasing the risks of osteoporosis including bone fractures.
Therefore, the present study was undertaken with an objective to assess the Beneficial effect of calcium supplementation on the bone mineral density of calcium deficient adolescents.

\section{Methods and Materials}

\subsection{Selection of Subjects}

A total of 706 adolescent students, 468 males and 238 females, aged 11-16 years were randomly selected from $8^{\text {th }}$, $9^{\text {th }}$ and $10^{\text {th }}$ standards of different government schools of District Kurukshetra. Separate groups of male and female were formed, both of which were sub classified on the basis of age into two groups - group I (11 to 13 years) and group II (14 to 16 years). Female group I comprised of 97 subjects while Female group II comprised of 141 subjects. Similarly, Male group I comprised of 116 subjects while Male group II comprised of 352 subjects. Calcium intake and anthropometric measurements were done on these 706 subjects. BMD was applied on 409 subjects (those have low 
dietary calcium intake). Male group I had 72 and group II 239 subjects, whereas, female group-I and group II had 48 and 50 subject respectively. Among the 409 adolescent students on whom bone mineral density assessment was performed, 42 female and 72 male students were found to be osteopenic while 19 female and 54 male subjects were found to be on borderline. Both borderline and osteopenic subjects were considered for experimental trial. 48 female subjects and 65 male subjects volunteered for blood test and for participation in the experimental feeding trial. The feeding trial was performed on these select set of adolescent students. 48 female and 65 male subjects selected for experimental feeding trial were sub-divided into three groups, comprising one control and two supplemental fed groups COS (Calcium organic supplement), CIS (Calcium inorganic supplement). Distribution of subjects are given in Table 1.

Table 1. Distribution of subjects into sub groups, control, COS (Calcium organic supplement), CIS (Calcium inorganic supplement).

\begin{tabular}{lll}
\hline & Male & Female \\
\hline Control & 15 & 15 \\
COS & 22 & 15 \\
CIS & 28 & 18 \\
\hline
\end{tabular}

Supplements of calcium were given to the subjects of group II and III for a continuous duration of 60 days at the time of recess in schools.

Supplementation: Calcium (inorganic and organic) supplements were given to subjects of group II and III. Supplements were given for the period of 60 days on a daily basis. The inorganic form of calcium supplement was CCM (calcium citrate malate) tablet. It was purchased from the local medical store of Kurukshetra city and given to the subjects of group II. It was given to the subjects of group II over and under the supervision of expert doctors. It contains $250 \mathrm{mg}$ of calcium citrate malate salt. Organic form of calcium supplements was given to the subjects of group III. Calcium rich foods-sesame seeds and mawa were incorporated in til mawa laddoo. One laddoo was given to each subject of group III on a daily basis for 60 days.

\subsection{Anthropometric Measurements}

Weight measurements were measured for all subjects. Weight was measured in kilograms using methods of Jelliffe [1] and ICMR [2]. These anthropometric measurements were compared with ICMR, NCHS and other values which helped determine growth performance, prevalence and incidence of degree of malnutrition among the adolescent's (both males and females). BMI of these adolescents was also assessed following the classification given by James et al [4].

\subsection{Bone Mineral Density (BMD) Measurements}

The Bone mineral density of subjects was determined using p-DEXA (peripheral dual-energy x-ray absorptiometry) method and measured by Ultrasound Bone Densitometer CM-200. For this measurement, the X-rays were applied on the right leg's heel (calcaneus) bone. Bone Mineral Density, expressed in grams per centimetre square and $\mathrm{T}$ score, was recorded for each of the subjects among all groups before and after the intervention trail.

\subsection{Statistical Analysis}

Mean and standard deviation were calculated for bone mineral density separately for each group of males and females. Anova was calculated among all the groups and t-test was calculated between each group before and after the intervention trial. The statistical significance was defined as $\mathrm{p}<0.01$ and 0.05 .

\section{Results and Discussion}

Weight: Weight of subjects is shown in Table 1. Statistically non-significant variation in weight of each subgroups of male and female subjects (OCS and ICS) was noticed with their respective control subgroup as well as on comparing before and after values of male and female OCS and ICS subgroups after completion of intervention trial. In male and female subgroups, the highest per cent increase in weight i.e. 1.40 per cent, was recorded in the subjects of male OCS followed by 1.11 per cent in female ICS and 0.70 per cent in both male ICS and female OCS. Following study disclosed the similar outcome. Rozen et al [5] testified no significant changes in anthropometric variables (weight) was observed during the study period within and between the inorganic CS and placebo groups. One more study by Dibba et al [6] showed that there are no significant effects of the calcium carbonate supplements on weight. Cadogan et al [7] reported that no significant differences in increments in weight was observed between the control and milk supplemented groups.

Table 2. Mean \pm Standard Deviation and $t$ value of weight of selected subjects before and after feeding trial.

\begin{tabular}{lllll}
\hline Weight (kg) & & & \\
\hline \multirow{2}{*}{ Gender } & & $\begin{array}{l}\text { Group I } \\
\text { (Control) }\end{array}$ & $\begin{array}{l}\text { Group II } \\
\text { (COS) }\end{array}$ & $\begin{array}{l}\text { Group III } \\
\text { (CIS) }\end{array}$ \\
\hline \multirow{6}{*}{ Male } & Subjects & 15 & 22 & 28 \\
& Before & $43.33 \pm 6.62$ & $35.07 \pm 4.55$ & $42.71 \pm 9.51$ \\
& After & $43.35 \pm 6.66$ & $35.56 \pm 4.6$ & $43.01 \pm 8.59$ \\
& Mean change & $0.02+0.07$ & $0.49 \pm 0.13$ & $0.3 \pm 0.08$ \\
& \% change & $0.05 \%$ & $1.40 \%$ & $0.70 \%$ \\
& t-value & -5.551 & -2.383 & -4.236 \\
& P(T<=t) one- & 0.057 & 0.148 & 0.438 \\
& tail & 15 & 15 & 18 \\
& Subjects & $36.67 \pm 5.09$ & $37 \pm 2.56$ & $33.4 \pm 3.24$ \\
& Before & $36.7 \pm 5.12$ & $37.26 \pm 2.58$ & $33.77 \pm 3.38$ \\
& After & $0.03 \pm 0.05$ & $0.26 \pm 0.33$ & $0.37 \pm 0.48$ \\
& Mean change & $0.70 \%$ & $1.11 \%$ \\
& \% change & $0.08 \%$ & -2.383 & -4.236 \\
& t-value & -3.010 & 0.215 & 0.085 \\
\hline
\end{tabular}

**: The mean difference is significant at 0.01 level.

*: The mean difference is significant at 0.05 level.

Group-I: Control

Group-II: Organic calcium supplement

Group-III: Inorganic calcium supplement 


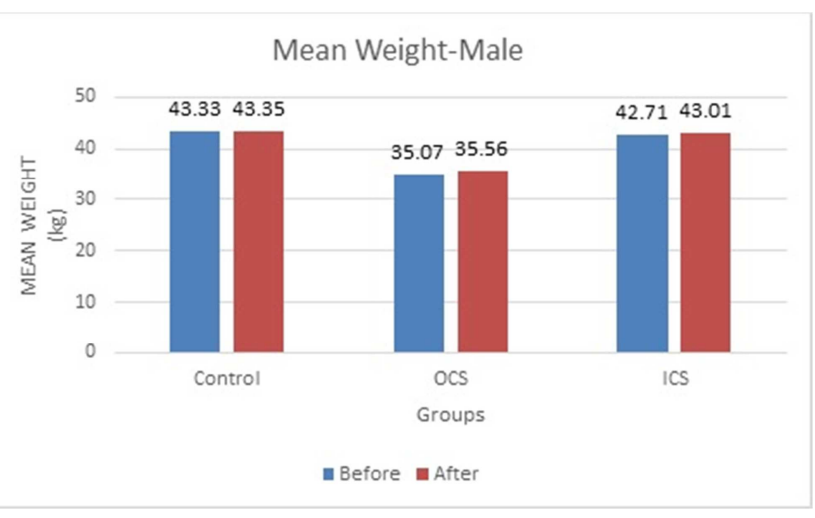

Figure 1. Mean $\pm S D$ for weight of the selected male subjects before and after feeding trial.

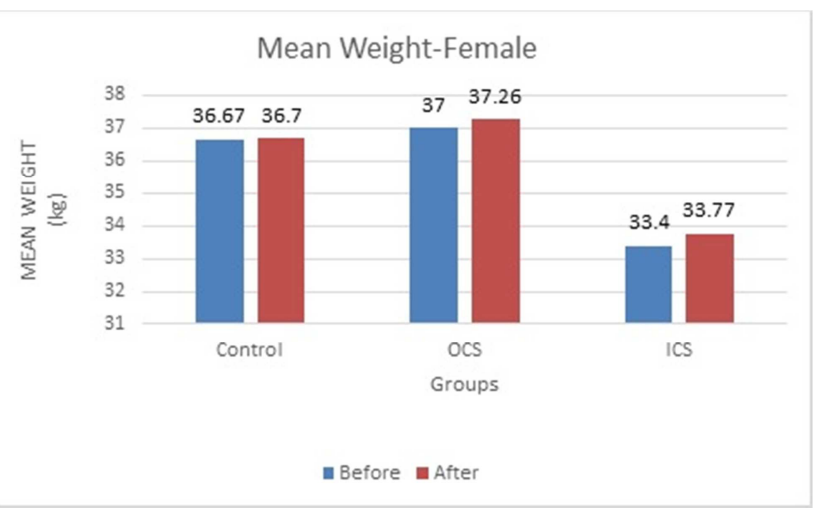

Figure 2. Mean $\pm S D$ for weight of the selected female subjects before and after feeding trial.
Bone mineral density: Before commencing the dietetic intervention trial with male subgroups (control, Organic Calcium supplement and Inorganic Calcium supplement) the mean bone mineral density (with T-Score in Table 2) of subjects were $0.522 \pm 0.03 \quad(-0.64 \pm 0.21), \quad 0.455 \pm 0.02 \quad(-$ $1.16 \pm 1.19)$ and $0.459 \pm 0.02 \quad(-1.22+0.14)$ respectively, whereas, with female subgroups (control, OCS and ICS) the mean bone mineral density (with T-Score) of subjects were $0.535 \pm 0.05 \quad(-0.48+0.29), \quad 0.448 \pm 0.01 \quad(-1.18+0.15)$ and $0.450 \pm 0.02(-1.18+0.09)$ respectively. After sixty days dietetic intervention trial with male groups (control, OCS and ICS) the mean bone mineral density (with T-Score) of subjects were $0.531 \pm 0.05 \quad(-0.61 \pm 0.18), \quad 0.523 \pm 0.04 \quad$ ($0.53 \pm 0.29)$ and $0.517 \pm 0.15 \quad(-0.88 \pm 0.39)$ respectively, whereas, the mean bone mineral density (with T-Score) of corresponding female subgroups was $0.537 \pm 0.04$ ($0.47+0.16), \quad 0.535 \pm 0.05 \quad(-0.48+0.8)$ and $0.496 \pm 0.04$ $0.52+0.6) \mathrm{gm} / \mathrm{cm}^{2}$ respectively. The respective percentage increase in mean BMD (with T-Score) of male subjects in control, OCS and ICS were 1.72 (4.68\%), 14.94 (54.31\%) and $12.64(27.86 \%)$ per cent, while, the percentage increase in mean BMD (with T-Score) of female subjects in control, OCS and ICS were 0.37 (2.08\%), 19.41 (59.32\%) and 10.22 $(55.93 \%)$ per cent respectively.

Efficacy of the intervention for increasing T-Score value was found maximum in female subgroup OCS (59.32\%) and minimum in male subgroup ICS $(27.86 \%)$ followed by female subgroup CIS (55.93\%) and male subgroup OCS $(54.31 \%)$ respectively.

Table 3. Mean \pm Standard Deviation and t-value for Bone mineral density (BMD) and T-Score of selected subjects before and after feeding trial.

\begin{tabular}{|c|c|c|c|c|c|c|c|}
\hline \multirow{2}{*}{ Gender } & & \multicolumn{2}{|c|}{ Group I (Control) } & \multicolumn{2}{|l|}{ Group II (OCS) } & \multicolumn{2}{|l|}{ Group III (ICS) } \\
\hline & & BMD $\left(\mathrm{gm} / \mathrm{cm}^{2}\right)$ & T-Score & BMD $\left(\mathrm{gm} / \mathrm{cm}^{2}\right)$ & T-Score & BMD $\left(\mathrm{gm} / \mathrm{cm}^{2}\right)$ & T-Score \\
\hline \multirow[t]{6}{*}{ Males } & Subject & 15 & & 22 & & 28 & \\
\hline & Before & $0.522 \pm 0.03$ & $-0.61 \pm 0.18$ & $0.455 \pm 0.02$ & $-1.16 \pm 1.19$ & $0.459 \pm 0.02$ & $-1.22+0.14$ \\
\hline & After & $0.531 \pm 0.05$ & $-0.64 \pm 0.21$ & $0.523 \pm 0.04$ & $-0.53 \pm 0.29$ & $0.517 \pm 0.15$ & $-0.88 \pm 0.39$ \\
\hline & Mean change & $0.009 \pm 0.064$ & $0.03 \pm 0.12$ & $0.068+0.12$ & $0.64 \pm 0.40$ & $0.058 \pm 0.049$ & $0.34 \pm 0.83$ \\
\hline & Percent change & $1.72 \%$ & $4.68 \%$ & $14.94 \%$ & $54.31 \%$ & $12.64 \%$ & $27.86 \%$ \\
\hline & t-value & -0.34 & -0.60302 & -4.44 & -5.02312 & -2.902 & -1.7153 \\
\hline \multirow[t]{7}{*}{ Female } & Subject & 15 & & 15 & & 18 & \\
\hline & Before & $0.535 \pm 0.05$ & $-0.48+0.29$ & $0.448 \pm 0.01$ & $-1.18+0.15$ & $0.450 \pm 0.02$ & $-1.18+0.09$ \\
\hline & After & $0.537 \pm 0.04$ & $-0.47+0.16$ & $0.535 \pm 0.05$ & $-0.48+0.8$ & $0.496 \pm 0.04$ & $-0.52+0.6$ \\
\hline & Mean change & $0.002 \pm 0.016$ & $-0.01 \pm 0.27$ & $0.087 \pm 0.063$ & $0.7 \pm 0.31$ & $0.046 \pm 0.049$ & $0.66+-0.3$ \\
\hline & Percent change & $0.37 \%$ & $2.08 \%$ & $19.41 \%$ & $59.32 \%$ & $10.22 \%$ & $55.93 \%$ \\
\hline & t-value & -0.36 & -0.38623 & -3.081 & -2.12024 & -3.955 & -3.30057 \\
\hline & $\mathrm{P}(\mathrm{T}<=\mathrm{t})$ one-tail & 0.3655 & 0.35633 & $0.0137 *$ & 0.05066 & $0.0084 * *$ & $0.01073 *$ \\
\hline
\end{tabular}

**: The mean difference is significant at 0.01 level.

*: The mean difference is significant at 0.05 level.

Group-I: Control

Group-II: Organic calcium supplement

Group-III: Inorganic calcium supplement

Table 4. Analysis of variance for T-Scores (BMD) level of selected male subjects before and after feeding trial.

\begin{tabular}{|c|c|c|c|c|c|c|c|c|c|c|c|c|}
\hline & Before & & & & & & After & & & & & \\
\hline Source of Variation & SS & df & MS & $\mathbf{F}$ & P-value & F crit & SS & Df & MS & $\mathbf{F}$ & P-value & F crit \\
\hline Between Groups & 0.090 & 2 & 0.044792 & 0.844 & 0.435 & 3.145258 & 1.466 & 2 & 0.732975 & 6.610 & $0.002 * *$ & 3.145258 \\
\hline Within Groups & 3.290 & 62 & 0.053061 & & & & 6.875 & 62 & 0.110882 & & & \\
\hline
\end{tabular}


Table 5. Analysis of variance for T-Scores (BMD) level of selected female subjects before and after feeding trial.

\begin{tabular}{|c|c|c|c|c|c|c|c|c|c|c|c|c|}
\hline & Before & & & & & & After & & & & & \\
\hline Source of Variation & SS & df & MS & $\mathbf{F}$ & P-value & F crit & SS & Df & MS & $\mathbf{F}$ & P-value & F crit \\
\hline Between Groups & 0.085 & 2 & 0.042674 & 0.110 & 0.896 & 3.204317 & 4.757 & 2 & 2.378667 & 60.497 & $1.76 \mathrm{E}-13^{* *}$ & 3.204317 \\
\hline Within Groups & 17.443 & 45 & 0.387617 & & & & 1.769 & 45 & 0.039319 & & & \\
\hline Total & 17.528 & 47 & & & & & 6.527 & 47 & & & & \\
\hline
\end{tabular}

Table 6. Multiple comparison for BMD T-Score of selected male and female subjects after experimental trial (Tukey).

\begin{tabular}{|c|c|c|c|c|c|c|}
\hline Dependent Variable & Gender & Compar & & Mean Difference & Tukey HSD Q Statistic & P Value \\
\hline \multirow{4}{*}{ BMD } & \multirow{2}{*}{ Male } & \multirow[b]{2}{*}{ Control } & OCS & 0.013 & 11.688 & $0.001 * *$ \\
\hline & & & ICS & 0.007 & 13.681 & $0.001 * *$ \\
\hline & \multirow{2}{*}{ Female } & \multirow{2}{*}{ Control } & OCS & 0.049 & 4.264 & $0.012 *$ \\
\hline & & & ICS & 0.010 & 0.954 & 0.761 \\
\hline
\end{tabular}

**: The mean difference is significant at 0.01 level.

*: The mean difference is significant at 0.05 level.

Group-I: Control

Group-II: Organic calcium supplement

Group-III: Inorganic calcium supplement

Statistical analysis of T-Score before and after feeding trial indicated, that for males, a significant difference was observed in calcium organic supplement $(\mathrm{p}=0.0006)$, while, no significant difference was observed for male's control and inorganic calcium supplement. While, in females indicated significant difference for OCS $(\mathrm{p}=0.0137)$ and ICS $(p=0.0084)$ while no significant difference was observed for control. Further analysis by post hoc Tukey test indicated significant difference in mean BMD-T Score values of male subgroups OCS $(p=0.001)$ and ICS $(p=0.001)$ with their control group, while, female subgroup OCS $(\mathrm{p}=0.012)$ had significant difference with its control group and subgroup ICS non-significant difference with its control group.

Similar findings were reported by following studies. Study by Chan et al [8] had reported that the dairy supplement group had higher intake of calcium than control subjects. The dairy group had significantly greater increases in bone mineral density in total body bone mineral $(14.2 \% \pm 7.0 \%$ vs $7.6 \% \pm 6.0 \%$ ) than control subjects. Young girls whose dietary calcium intake was provided primarily by dairy products at or above the recommended dietary allowances had an increased rate of bone mineralization. In another study by Matovic et al [9], it is reported that there was a more pronounced increase in bone mass over time in the calciumsupplemented group $(1640 \mathrm{mg} \mathrm{Ca} / \mathrm{d})$ than in the control group i.e. $750 \mathrm{mg} \mathrm{Ca} / \mathrm{d}$. Johnston et al [10] also found that calcium supplementation had a positive effect on the rate of increase in bone mineral density at several skeletal sites in pubertal age. The subjects who were given supplements received on average $719 \mathrm{mg}$ more calcium per day than their twins and had an increase of about 3 per cent more mineral in the radius during the three-year study period.

Bone mineral acquisition was significantly greater in the group given milk supplements than in the control group. The intervention group had greater percentage increases of total body bone mineral density $(9.6 \%$ (SD 1.9\%; $95 \%$ confidence interval $9.0 \%$ to $10.2 \%) \vee 8.5 \%(2.7 \% ; 7.6 \%$ to $9.4 \%)$; $\mathrm{p}=0.017$ ). Expressed in absolute terms, the respective increases were $0.090(0.020 ; 0.084$ to 0.096$) v 0.081(0.025$;
0.072 to 0.089$) \mathrm{g} / \mathrm{cm} 2$ for total body bone mineral density $(p=0.021)$ [7], [15]. Findings by other studies [5], [19] concluded that calcium supplementation of post-menarcheal girls age of $14+.5$ year with habitual low calcium intakes $<800 \mathrm{mg}$ /day enhances bone mineral acquisition especially in girls $>2$ yr past the onset of menarche. Another study carried out by Marwaha et al [11], provides information on BMD in peripheral sites (calcaneum) in healthy Indian girls. It was found that the mean BMD values in LSES subjects were $0.358 \pm 0.066 \mathrm{~g} / \mathrm{cm} 2$ while those in the USES subjects were $0.389 \pm 0.067 \mathrm{~g} / \mathrm{cm}^{2}$, whereas the mean values of BMD in 12-16-year-old girls from China (study by Afgani et al [13], Chan G. M. [14]) was $0.34 \pm 0.05 \mathrm{~g} / \mathrm{cm}^{2}$. In additional study by Marwaha et.al [12], Comparison of BMD at calcaneum in Indian children with data from healthy Caucasian children in the United Kingdom acquired with the same model of densitometer showed that LSES subjects had lower values and USES subjects had higher values. In the study conducted in China [13], the mean BMD values in 12-16 yr old girls were $0.47 \pm 0.06 \mathrm{~g} / \mathrm{cm} 2$; values which were higher than those of LSES subjects $(0.429 \pm 0.064 \mathrm{~g} / \mathrm{cm} 2)$ and lower than USES subjects $(0.488 \pm 0.083 \mathrm{~g} / \mathrm{cm} 2)$ from that study.

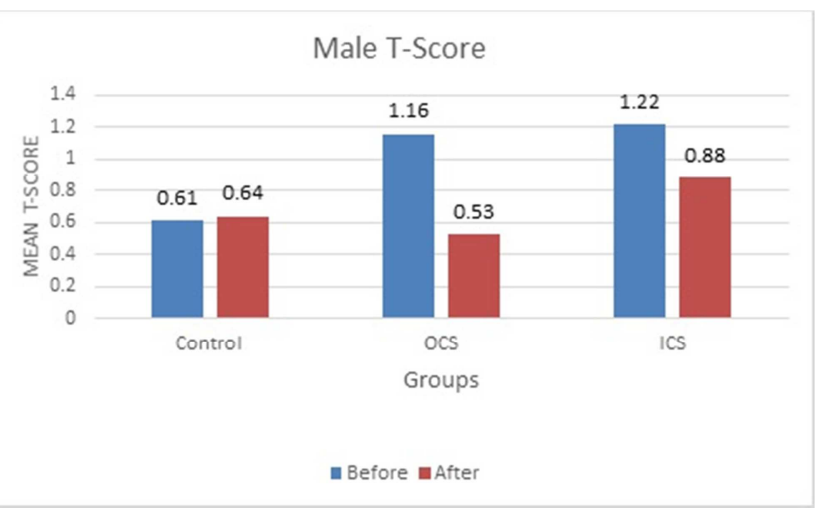

Figure 3. Mean $\pm S D$ for BMD -T Score of the selected male subjects before and after feeding trial. 


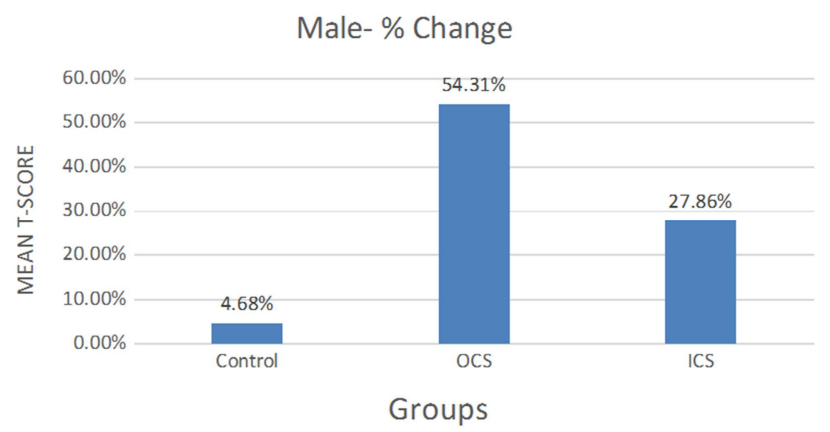

Figure 4. Change in percentage of BMD -T Score of the selected male subjects before and after feeding trial.

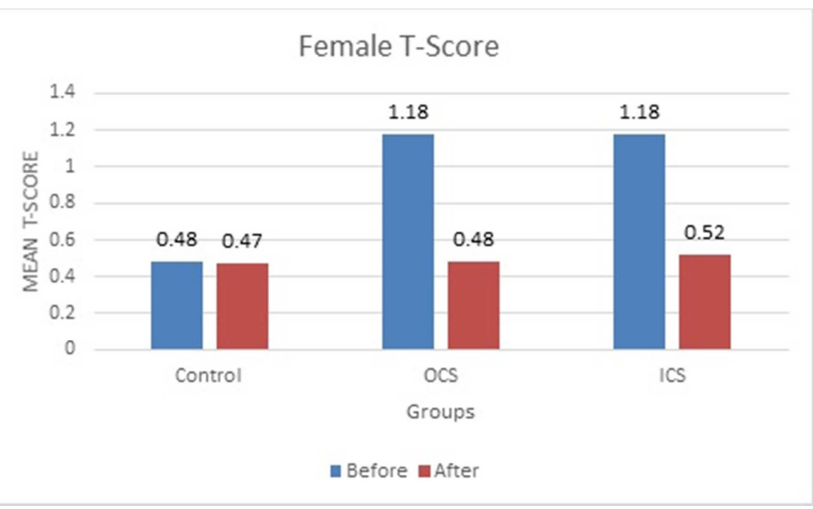

Figure 5. Mean $\pm S D$ for BMD -T Score of the selected female subjects before and after feeding trial.

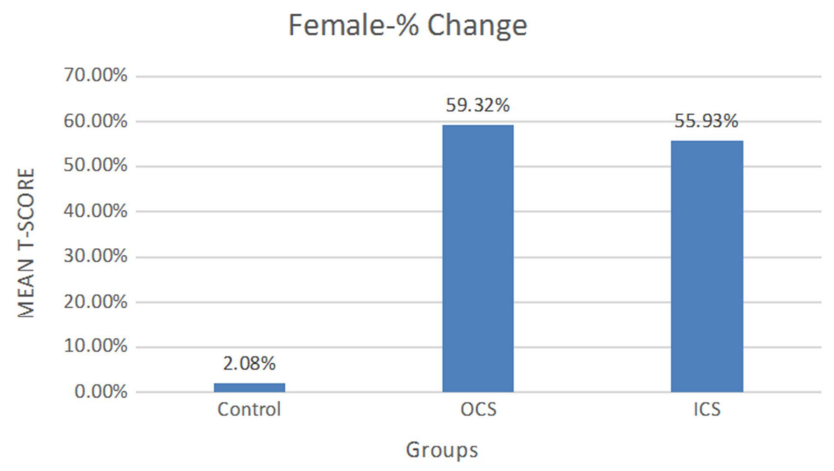

Figure 6. Change in percentage of BMD -T Score of the selected female subjects before and after feeding trial.

\section{Conclusion}

Significant increase in Bone mineral density were observed among male and female subgroups after intervention. Organic supplements had greater effect on BMD. The respective percentage increase in mean BMD (with T-Score) of female subjects have more than male subjects.

\section{References}

[1] Jelliffe, O. B. 1996. The Assessment Of Nutritional Status Of The Community Monograph Series no. 53. Geneva: World health organization.
[2] ICMR (1992) Nutrient requirements and recommended dietary allowances for Indians. Indian Council Of Medical Research, New Delhi.

[3] ICMR. 2010. NUTRIENT REQUIREMENTS AND RECOMMENDED DIETARY ALLOWANCES FOR INDIANS. HYDERABAD: NATIONAL INSTITUTE OF NUTRITION.

[4] James, W. P. T., Ferro-Liuzzi and Waterlow, J. C. 1988. "Definition of chronic energy deficiency in adults- report of working party of the intervention dietary energy consultation group." Am. J. Clin. Nutr. 42: 969-981.

[5] Rozen, G. S., Rennet, G., Dudiuk-Gad, R. P., Ish-Shalom, N., Diab, G., Batia, R., Ish-Shalom, S. 2003. "Calcium supplementation provides an extended window of opportunity for bone mass accretion after menarche." Am J Clin Nutr 78: 993-998.

[6] Dibba B., Prentice A., Ceesay M. Stirling D. M., Cole T. J. and Poskitt E. M. E. 2000. "Effect of calcium supplementation on bone mineral accretion on Gambian children accustomed to a low calcium diet." Am J Clin Nutr 71: 544-549.

[7] Cadogan, J., Eastell, R., Jones, N. and Baker, M. E. 1997. "Milk intake and bone mineral acquisition in adolescent girls: randomised, controlled intervention trial." BMJ 315: 1255.

[8] Chan G. M., MD, Hoffman K., McMurry M., MS. 1995. "Effects of dairy products on bone and body composition in pubertal girls." The Journal of Pediatrics 126 (4): 551-556.

[9] Matkovic V., Jasminka Z I., Mark B A., Lily C H., Michael A T., Becky J L., and Prem K Goel. 1990. "Factors that influence peak bone mass formation- A study of calcium balance and the inheritance of bone mass in adolescent females." Am J Clin Nutr.

[10] Johnston, C. C., J. Z. Miller, C. W. Slemenda, T. K. Reister, S. Hul, and J. C. Christian. 1992. "Calcium supplementation and increases in bone mineral density in children." N Engl J Med 327: 82-87.

[11] Marwaha, R. K., Tondon, N., Reddy, D. H. K., Mani, K., Puri, S., Aggrawal, N. 2007. "Peripheral bone mineral density and its pridictors in healthy schoolgirls from two socioeconomic groups in Delhi." Osteoporosis Int 18: 375-383.

[12] Marwaha, R. K. and Sripathy, G. 2008. "Vitamin D \& bone mineral density of healthy school children in northern India." Indian J Med Res 127: 239-244.

[13] Afghani, A., Xie, B., Wiswell, R. A., Gong, J., LiV, AndresonJohnson, C. 2003. "Bone mass of Asian adolescents in China: influence of physical activity and smoking." 35: 720-729.

[14] Chan, G. M. 1991. "Dietary Calcium and Bone Mineral Status of Children and Adolescents." Am J Dis Child 145 (6): 631634.

[15] Ebtissam M. S. Manal A. M., Mai M. Y., Hala S. M., Samar M. E. S., Effect Of Diet Quality On Bone Mineralization In Obese Egyptian Children And Adolescents [Journal] // Journal of Applied Sciences Research. - 2012. - 5: Vol. 8. - pp. 28122820 .

[16] Greer F. R. MD, Nancy F. Krebs, MD, and the Committee on Nutrition Optimizing Bone Health and Calcium Intakes of Infants, Children, and Adolescents [Journal] // AMERICAN ACADEMY OF PEDIATRICS. - February 2006. - 2: Vol. 117. 
[17] Goulding A Cannan R, Williams SM, Gold EJ, Taylor RW, Lewis-Barned NJ Bone mineral density in girls with forearm fractures [Journal] // J Bone Miner Res. - 1998. - Vol. 13. - pp. 143-148.

[18] Goulding A Jones IE, Taylor RW, Williams SM, Manning PJ. Bone mineral density and body composition in boys with distal forearm fractures: a dual-energy x-ray absorptiometry study. [Journal] // J Pediatr. - 2001. - Vol. 515. - p. 139:509.
[19] S. A. Ibrahim, M. A. Samy, M. K. Matter1, and A. O. L. Saleh. 2011. "Bone mineral density in Egyptian adolescents and adults with short stature: results of a national survey." Eastern MediterraneanHealth Journal 17: 8. 